\title{
Alternativo
}

\section{HISTÓRIA E MEMÓRIA DE UM CALDEIRÃO DE CRIANÇAS}

Hugo de Melo Rodrigues (1)

\section{Apresentação}

Em 1983, Alfons Lonsing e Bernadete Bezerra Lonsing, juntamente com os filhos: Agnes, Marcos, Paulo e Roberto, iniciaram um trabalho coletivo com a comunidade do bairro Novo Juazeiro, em Juazeiro do Norte, reunindo-se semanalmente com as famílias para discutir os problemas existentes.

Neste mesmo ano, o casal acolheu em sua casa 04 crianças abandonadas pela mãe, que viviam em condições miseráveis. A partir deste período, o trabalho do casal começou a se expandir.

Em 12 de outubro de 1987 a "Fundação Caldeirão da Criança" foi instituída legalmente e, no ano de 2007 a entidade encerra suas atividades. No decorrer deste período foram acolhidas mais de duas mil e quinhentas crianças e adolescentes, com histórias de vida marcadas pelo abandono e sofrimento. $\mathrm{Na}$ verdade, são frutos de uma sociedade excludente, pautada nos princípios da desigualdade, individualismo e da injustiça social.

A entidade atuava junto à comunidade Juazeirense, na execução de programas sócioeducativos, em regime de abrigo, para crianças abandonadas ou extremamente carentes.

A Fundação colocava-se a disposição da comunidade, em apoio a essas crianças, fazendo o papel de uma grande família, além de favorecer o acesso a atividades diversas proporcionadas por voluntários. Essas atividades constavam de: teatro, pintura, artesanato, jardinagem, esporte, circulo de leitura e reforço escolar.

Para serem admitidas na instituição, as crianças, eram inicialmente encaminhadas pelo Juizado de Menores e, posteriormente pelo Conselho Tutelar do município. 
Ao longo de sua trajetória, o Caldeirão enfrentava dificuldades, porém alcançava resultados significativos, tais como: jovens que chegavam sem saber ler e escrever e posteriormente concluíam o ensino médio; outros concluíam curso superior; alguns constituíam família; outros desenvolviam habilidades em artes cênicas, computação e artes marciais.

Vale ressaltar ainda que a instituição, entre outras tarefas, encaminhava as crianças para o ensino regular e para o reforço escolar, além de desenvolver ações pedagógicas que contribuíam para preencher as lacunas existentes nas escolas destinadas às crianças de baixa renda, assim contribuía significativamente para a redução do analfabetismo, da repetência e da evasão escolar.

Dessa forma, as razões que fundamentaram a escolha da entidade para desenvolver o presente estudo se faz, principalmente, por se tratar da única entidade da região do Cariri a trabalhar com a criança e o adolescente abandonado em regime de abrigo, possibilitando ainda conhecer a história do Caldeirão da Criança e responder a alguns questionamentos relacionados a essa atividade social, tais como: a) Caracterizar o Caldeirão da Criança; b) Apresentar como surgiu a instituição; c) Definir o porquê do nome Caldeirão.

Para a coleta de dados, realizou-se a leitura de documentos sobre a entidade, bem como a análise de cartas e documentos dos fundadores. A pesquisa de campo foi um outro importante instrumento utilizado na investigação.

\section{Histórico da Fundação Caldeirão da Criança}

A Fundação Caldeirão da Criança foi uma instituição filantrópica, de utilidade pública municipal e estadual, com Registro no Conselho Municipal e Nacional de Assistência Social. Sendo um abrigo de crianças carentes, geralmente filhos de mães solteiras. Funcionava sob a coordenação de seus fundadores - Alfons Lonsing e Bernadete Bezerra Lonsing.

A entidade visava oferecer, aos desfavorecidos socialmente, a possibilidade da convivência em uma grande família.

Vale ressaltar que o Caldeirão acolhia crianças de toda região do Cariri e de outros estados, cuidando até à independência sócio-econômica. 
O Alfons definia a entidade como sendo uma obra divina. "A Fundação Caldeirão da Criança é uma obra da Divina Providência, dada como patrimônio à comunidade com as bênçãos de Deus e garantias do Ministério Público".

O Caldeirão tinha como finalidade principal a promoção e atendimento às crianças carentes. Assumia o papel de família propondo a acompanhar estas crianças integralmente até que as mesmas estivessem capacitadas a viver por conta própria ou retornassem para os familiares, conforme termo de encaminhamento do Conselho Tutelar.

Em nível formal de delineamento da sua missão enquanto órgão de assistência social, o Caldeirão demarcava os seguintes objetivos permanentes (Estatuto, cap. 1, art. 3):

- Assistir ao desenvolvimento integral de todas as faculdades mentais e físicas da criança abandonada e carente, sem qualquer discriminação, até a sua independência sócio-econômica;

- Zelar para que todos concluam os estudos do Ensino Médio e encaminhar os adolescentes, conforme tendências, à aprendizagem profissional e estudos superiores;

- Estimular os educandos desde pequenos a ajudarem-se mutuamente, ou seja, os maiores auxiliarem os menores na execução das tarefas escolares e caseiras, formando uma comunidade solidária com espírito de Família;

- Conscientizar a sociedade para um maior respeito à vida em desenvolvimento.

De acordo com os fundadores, o Caldeirão surgiu da "Dinâmica da vida", não sendo projeto ou algo planejado. Para eles, representa um "Plano Divino". Nasceu da possibilidade de ajudar aos mais necessitados, principalmente as crianças abandonadas, conforme esclarece Alfons “(...) nasceu como resposta ao Evangelho ao desafio da criança abandonada em nosso meio e tem como finalidade principal à promoção e atendimento integral a criança carente e abandonada, que não encontra acolhida em outras instituições."

Em setembro de 1982 chega a Juazeiro do Norte, cidade do interior cearense, o alemão Alfons e sua esposa a Ir. Bernadete, brasileira e juazeirense. “(...) De modo que chegamos em Juazeiro no dia dois de setembro. No dia nove passamos para a casinha que nos arranjaram que fica um pouco afastada, a seis quilômetros do centro, num bairro novo: Novo Juazeiro." (BERNADETE BEZERRA LONSING, 13.11.1982)

Com o propósito de servir ao próximo, Alfons e Bernadete não sabiam ainda o que estava reservado para a vida deles e em 1983 iniciaram um trabalho coletivo no Bairro Novo Juazeiro. 
Da vivência das CEBs - Comunidades Eclesias de Base, surge a "Comunidade 131", que recebe este nome por se tratar do número da rua onde moravam e se reuniam semanalmente com as famílias vizinhas para discutirem os problemas existentes. Era o auge da seca.

(...) Não se pode mais rezar: Ensinai-nos a repartir com aqueles que não tem. Reza-se: ensinai-nos a repartir aquilo que não tem. (...) E nós meu amigo, estamos no mesmo barco. Mas não me sinto infeliz, nem inútil. Onde posso jogar um pouco de óleo em uma ferida o faço. Não posso levar o ferido para uma estalagem, como o Bom e rico samaritano, mas dou o óbolo da viúva. (BERNADETE BEZERRA LONSING, 13.11.1982)

A origem das CEBs remonta aos anos de 1960, como uma alternativa de trabalho social, onde a comunidade e a igreja católica procuravam solucionar em conjunto o problema da desigualdade social. Para conceituar as CEBs, Betto apresenta três fatores fundamentais, conforme citação.

Primeiro, são comunidades, porque reúnem pessoas que têm a mesma fé, pertencem à religião católica e moram na mesma região. Segundo, são eclesiais, em razão de sua vinculação à Igreja, como instituição. Terceiro, são de base, porque são integradas por pessoas que trabalham em profissões simples, como: donas-de-casa, operários, jovens, desempregados, aposentados e profissionais provindos dos setores de serviços. (BETTO apud DELMIRO, 1999, p. 113)

De acordo com Leonardo Boff (1982), faz-se necessário compreender o que é uma Comunidade Eclesial de Base. Afirma que é mais que um instrumento de evangelização ou extensão do sistema eclesiástico, é a própria Igreja se realizando na base do povo. Acredita que o povo, pobre e crente, com sua cultura, sua consciência de classe explorada, com suas tradições, recria, a partir da fé cristã, a Igreja como comunidade que se reúne ao redor da leitura da Palavra de Deus, colocando em comum seus problemas e iluminando-os por esta mesma palavra que, discutida e aprofundada, ajuda a elaborar saídas para a situação aflitiva que sofre.

No início das atividades com a "Comunidade 131 " não se pensava em uma instituição para acolher crianças carentes. Neste mesmo ano, o casal, acolheu em sua casa crianças abandonadas pela mãe, que viviam em condições precárias.

Bernadete conta que encontrou uma mulher desesperada com 04 crianças. Ao conversar com a mulher, soube que se tratava de uma família abandonada pelo pai. A mãe, 
sem ter o que oferecer para os filhos se alimentarem e ameaçada de despejo da casa onde morava, dizia que iria procurar veneno para dar aos filhos e para si mesma, pondo assim fim em todo aquele sofrimento. Bernadete conseguiu ajudá-la, levando-os para sua casa. Providenciou para que tomassem banho e fossem alimentados. Foram os primeiros a serem abrigados e assim começou o Caldeirão. Momento este que foi registrado nos versos do poeta popular Francisco de Assis Alves dos Santos (1999).

(...) D. Beta ao sair, para ir ao mercantil, Deu de cara com um fato, não tão raro no Brasil, Uma mulher maltratando, um pobre ser infantil.

Uma mãe e quatro filhos, um chorando, outro também, D. Beta lhe parou, pra tentar fazer o bem, Lhe perguntou desse jeito: 'O qu' é que a garota tem'?

A resposta que ela ouviu, não foi muito educada:

'Minha vida não tem graça, sem comida e sem nada, Eu vou comprar um veneno, vou morrer envenenada,

E mato eles também, nós não somos mesmo gente.

Isso abalou D. Beta, e ali surgiu de repente, O Caldeirão da Criança, sentia, era a semente.

Levou eles para casa, para lhes alimentar, A mulher e os garotos tinham um lar pra morar,

O Caldeirão da Criança começava a se formar (...)

De início as despesas foram supridas pelo trabalho de Alfons na colocação de papel de parede, enquanto que Bernadete fazia trabalhos de tapeçaria. Como o número de crianças foi aumentando, sentiram a necessidade de conseguir recursos extras. Em viagem à Alemanha, sua terra natal, Alfons conseguiu doações de familiares e amigos que se comprometeram a ajudá-los neste trabalho social.

Daí em diante começaram a chegar mais meninos e meninas carentes, a maioria trazida pelo juizado de menores do município. As condições de alojamento e manutenção já não eram mais suficientes, mas sentiam que não podiam deixar de atender aquelas crianças, já que o destino destas seria a realidade sombria das ruas.

Em setembro de 1987, Alfons convocou uma reunião no juizado de menores. Convidou diversas pessoas com o objetivo de fundar uma associação para garantir uma personalidade jurídica ao trabalho desenvolvido. Compareceram 13 pessoas, não queriam comprometer-se diretamente, mas ficou decidida a instituição de uma fundação que recebeu o 
nome de CALDEIRÃO DA CRIANÇA. Houve o compromisso de algumas ajudas financeiras. De acordo com Alfons, este compromisso não continuou por muito tempo, pois a cada procura, obtinha a resposta: "venha amanhã" até entrar no exercício findo. Outras pessoas ficaram ajudando esporadicamente.

Com o tema da Campanha da fraternidade da CNBB - Conferencia Nacional dos Bispos do Brasil, para o ano de 1987 de "Quem acolhe o menor, a mim acolhe", o apelo foi feito, clamando o povo de Deus para ajudar as crianças abandonadas.

Assim a FUNDAÇÃO CALDEIRÃO DA CRIANÇA foi instituída oficialmente no dia 12 de outubro de 1987 por ocasião da missa em homenagem a Padroeira do Brasil, Nossa Senhora Aparecida, celebrada por Frei Roberto na igreja do MENINO JESUS DE PRAGA no Novo Juazeiro.

\section{Origem do nome Caldeirão}

O que caracteriza a pessoa é o "nome" e este torna-se referência, agregando uma pessoa à outra, a uma instituição, a uma rua. Expressão esta bem definida nos versos de João Cabral de Melo Neto em Morte e Vida Severina (1994). “O meu nome é Severino, não tenho outro de pia. Como há muitos Severinos, que é santo de romaria, deram então de me chamar Severino de Maria."

O nome é a primeira perda que ocorre para crianças ou adultos que moram nas ruas. Geralmente são identificados por alguma característica física ou por um apelido. Há uma continuidade desse fato em algumas escolas que reconhecem os seus alunos por número e não por nome. É ainda no sistema presidiário que se concretiza a identificação deste número. Também no período da Segunda Guerra Mundial os judeus foram marcados por números, como ocorre também com a marcação de animais.

Os fundadores utilizam três justificativas para a definição do nome "Caldeirão": grande panela, homenagem ao Caldeirão do Beato José Lourenço e o sentido de Caldeirão para a filosofia chinesa.

Em primeiro lugar, a relação com a idéia de "grande panela" que alimenta muita gente, resgata a situação do povo pobre, onde a primeira preocupação é o estômago. No período de fundação da entidade, o Brasil foi classificado como a oitava economia do mundo. Período de seca, de miséria, de fome, motivo pelo o qual o Caldeirão era muitas vezes procurado. A miséria está bem apresentada nos versos de Manuel Bandeira intitulado "O bicho". 


\author{
Vi ontem um bicho \\ Na imundície do pátio \\ Catando comida entre os detritos. \\ Quando achava alguma coisa, \\ Não examinava nem cheirava: \\ Engolia com voracidade. \\ O bicho não era um cão, \\ Não era um gato, \\ Não era um rato. \\ O bicho, meu Deus, era um homem.
}

(BANDEIRA apud CEREJA \& MAGALHÃES, 1999, p. 29)

Em segundo lugar, tinha como objetivo também, prestar uma homenagem ao Beato José Lourenço, homem do povo, que se engajou em um trabalho comunitário na região do Cariri, que assustou os poderosos. A rua da sede da instituição é denominada Beato José Lourenço por solicitação de Alfons junto a Câmara de vereadores de Juazeiro do Norte, cujo Projeto de Lei foi apresentado em 23.08.1993, pelo vereador Francisco Gilson de Souza. No livro: "Um beato líder, narrativas memoráveis do Caldeirão", o autor faz referências ao Caldeirão da Criança e a rua Beato José Lourenço.

Em 1987, é criado o movimento 'Caldeirão da Criança' em Juazeiro do Norte, inspirado na memória do Caldeirão de José Lourenço, objetivando trabalhar com crianças abandonadas. (...) Por outro lado, o Beato José Lourenço virou nome de rua em Juazeiro do Norte (Bairro Tiradentes, próximo ao presídio) (...) (CORDEIRO, 2004, p. 115)

O Caldeirão do Beato, foi uma comunidade messiânica, de caráter socialista surgida no Cariri cearense sob a liderança de um paraibano negro, pobre, filho de sertanejos, chamado José Lourenço Gomes, o beato, conhecido por José Lourenço, cuja comunidade por ele construída abrigou retirantes da seca, e foi covardemente destruída em 1937 pelo Governo Menezes Pimentel com o apoio da igreja e latifundiários.

$\mathrm{Na}$ comunidade camponesa do Caldeirão habitaram aproximadamente 1.700 pessoas. No início, era um pequeno grupo sob a liderança do Beato, em torno da devoção à Santa Cruz. Possuía um sistema de produção e distribuição de bens básicos (víveres, instrumentos, oportunidades de trabalho, moradia e "alimento para o espírito") com características de autogestão: 'tudo era de todos', e, pressupõe-se, de acordo com entrevistas 
realizadas com 'remanescentes', que não havia distinção entre dirigentes $e$ executantes do processo de produção. (...) (CORDEIRO, 2004, p. 44)

Em terceiro lugar, Alfons fundamenta o termo "Caldeirão" na filosofia chinesa, expressa no livro "I Ching". Nesta perspectiva a palavra Caldeirão é identificada como o símbolo da "Dinâmica da Vida", onde também se observa a valorização do espírito. Representa ainda "Caldeirão" como sendo a estrutura cultural da sociedade, a madeira que serve de combustível à chama.

\section{Considerações finais}

São muitos os problemas sociais existentes na conjuntura do país, principalmente considerando as dimensões geográficas que o Brasil possui. Parte destes problemas são solucionados por organizações não governamentais que são mantidas por recursos oriundos de doações estrangeiras. Uma dessas instituições foi o Caldeirão da Criança que sobreviveu durante 24 anos principalmente de doações vindas de campanhas realizadas em escolas e igrejas da Alemanha e que pela falta desses recursos entre outros motivos foi impossível a sua sobrevivência.

Com a intenção de reintegração do jovem à sociedade é que o Caldeirão lutou para atingir os seus ideais. Não contou com apoio financeiro necessário, sobreviveu principalmente de doações.

O Caldeirão surgiu como uma oportunidade que as crianças abandonadas encontravam para sair da fome e da miséria e com perspectiva de vida melhor.

O trabalho recebeu críticas também pela maneira como foi coordenado, tendo como fator principal o desenvolvimento da criança e do adolescente, o acompanhamento em família, a partilha e a solidariedade com os irmãos mais necessitados.

Mesmo com os inúmeros problemas surgidos e as dificuldades para a manutenção do trabalho, a entidade alcançou resultados significativos, e colaborou de maneira eficiente para garantir a oportunidade de uma vida melhor para as crianças que por lá passaram.

No início do estudo foram elencados alguns questionamentos e respondidos no decorrer do trabalho. A formação religiosa e a vivência em trabalhos de promoção humana foram fatores decisivos para dedicação, determinação e doação do casal para o acolhimento de crianças abandonadas. E uma das grandes características do Caldeirão foi a capacidade de servir aos excluídos, desprotegidos, de acolher crianças e adolescentes abandonados. 
Há um reconhecimento natural de gratidão pelos jovens que foram acolhidos no decorrer dos 24 anos de existência da entidade, porém há um vazio enorme e um sentimento de tristeza pelo fato da impossibilidade de continuidade da entidade.

Torna-se percebível a omissão das instituições governamentais por não garantir as condições necessárias para manutenção e continuidade dos trabalhos do Caldeirão da Criança.

As ações governamentais sejam elas na instância federal, estadual ou municipal, não conseguem atender de forma concreta e eficiente os problemas existentes e muitas vezes até se omitem de fazê-las. Não direcionar o apoio pedagógico e financeiro que estas instituições precisam é aceitar que a população carente fique à margem, encontrando na criminalidade condições de sobrevivência.

\section{Referências}

AGUIAR, Cláudio. Caldeirão: a guerra dos Beatos. 3ª ed. Rio de Janeiro: Calibán, 2000.

ARNS, Paulo Evaristo. Brasil: nunca mais. 14ª ed. São Paulo: Vozes, 1986.

BOFF, Clodovis et. alii. As comunidades de base em questão. São Paulo: Paulinas, 1997.

BOFF, Leonardo. As CEBs os partidos e o PT. Folha de São Paulo. São Paulo. 26.08.1982.

BRASIL. Estatuto da Criança e do Adolescente,1990. . Lei Orgânica de Assistência Social, 1993. . Natal 2003: Jesus nasceu e continua entre nós. Regional Nordeste I: CNBB, 2003. . Novo Código Civil. $1^{\mathrm{a}}$ ed. São Paulo: Ridel, 2003.

BRENER, Jayme. Leste Europeu: a revolução democrática. 1ª ed. São Paulo: Atual, 1991.

CEREJA, William Roberto; MAGALHÃES, Thereza Cochar. O bicho. V.1, $3^{\mathrm{a}}$ ed. São Paulo: Atual, 1999.

CEREJA, William Roberto; MAGALHÃES, Thereza Cochar. Canção amiga. V.3, $3^{\text {a }}$ ed. São Paulo: Atual, 1999.

CORDEIRO, Domingos Sávio de Almeida. Um beato líder: narrativas memoráveis do Caldeirão. $1^{\text {a }}$ ed. Fortaleza: Imprensa Universitária, 2004. . Caldeirão dos mitos. Olhares e saberes para compreender o fenômeno Padre

Cícero. Tendências - Caderno de Ciências Sociais. V.2 - No 1. Julho, Crato: URCA, 2004. 
DELMIRO, Ivaldinete de Araújo. CEBs: Espaço de fé, formação e cidadania. In: Essentia Revista de cultura, ciência e tecnologia da Universidade Estadual Vale do Acaraú. Sobral: Ano I - N.2- Junho/Novembro, 1999.

GIORDANI, Marco Pollo. Brasil: sempre. 1ª ed. Porto Alegre: Tchê!, 1986.

LINK, Paulo. Adolfo. Adolfo Kolping: novena. $1^{\text {a }}$ ed. São Paulo: Kolping.

NETO, João Cabral de Melo. Morte e Vida Severina. Obra completa. $1^{\text {a }}$ ed. Rio de Janeiro: Nova Aguilar, 1994.

O CELIBATO em debate na imprensa. SINAL - Publicação dos padres casados. Não assinada. Fortaleza, 1996.

PAZ, Renata Marinho. Cariri: campo fértil da Religiosidade popular. Olhares e saberes para compreender o fenômeno Padre Cícero. Tendências - Caderno de Ciências Sociais. V.2 $\mathrm{N}^{\mathrm{o}}$ 1. Julho, Crato: URCA, 2004.

RAMALHO, Braulio. O movimento estudantil no Ceará: de 1928 a 1968. $1^{\text {a }}$ ed. Fortaleza: $\mathrm{ABC}, 2002$.

RESENDE, Tomáz de Aquino. Roteiro do Terceiro Setor. Belo Horizonte: Publicare,1999.

SANTOS, Francisco de Assis Alves dos. O Caldeirão da Criança. Juazeiro do Norte, 1999.

SEVERINO, Antônio Joaquim. Metodologia do Trabalho Científico. 22 ${ }^{\mathrm{a}}$ ed., São Paulo: Cortez, 2002.

VEIGA, Sandra Mayrink, RECH, Daniel. Associações: como constituir sociedades sem fins lucrativos. Rio de Janeiro: DP\&A: Fase, 2001.

(1) Hugo de Melo Rodrigues é Historiador e Especialista em Psicologia Aplicada à Educação pela Universidade Regional do Cariri - URCA. E-mail: hugode@hotmail.com. 